\title{
Materials for outer shell of 1.170 GWh (1.00669 kilo ton TNT) fusion device - weight basis
}

\author{
Muhammad Musaddique Ali Rafique \\ Eastern Engineering Solutions Inc., Cambridge, MA USA
}

\begin{abstract}
With recent developments in fusion engineering, interest has sparked in development of fusion devices for deterrent. Enormous amount of energy generated by combining two light nuclei could be contained and manipulated at will to trigger and accelerate micro explosions (from shock wave, $\mathrm{x}$-rays or ion beam focusing) which finally result in full scale blast. Materials required to make such device are critical. They must possess high strength, high hardness, ductility, formability, drawability, and anisotropic properties. High entropy alloys (HEA) are new class of materials which nicely fulfils this requirement. Essentially, they are solid solutions of multi principal elements (usually $>5$ ) eliminating the need of base metal as in conventional alloys. This gives them many unique properties which may be tailored at will (heat treatment, cold rolling, precipitation, irradiation). They also exhibit excellent directional properties with formation of distinct bands along certain preferred crystallographic planes even in hexagonal close packed structures. These anisotropic properties are strong function of rolling, working, or forging (swaging) direction and can be utilized to benefit. This study encompasses making outer shell of a typical fusion device selected on the basis of the weight, which is a function of area of pay load bay of carrier aircraft.
\end{abstract}

Keywords: bands, anisotropy, cold rolling, texture, pole figures, fusion

\section{Introduction}

Fusion is promising to be an important source of limitless energy for future. It is fuel efficient, quick, and voluminous process with ability to be scaled up and controlled to yield high amount and throughput of energy. In its native form, it may be harnessed to build reactors (contained devices) or untamed form to build devices [1-3] which is an area of interest here. Historically, these devices have been made in many ways such as famous cylindrical configuration (Teller Ulam design (Fig 1)) [4], modified Teller Ulam design (Ivy Mike (Fig 2 and 3)) [4], oval, cone and dual cone configuration [5-7] all on the basis of principle to contain plasma [8] or X-ray shock wave produced, focus them (e.g. by curved walls [9] or implosion of disk [10]) for [11] ignition of micro explosions $[10,12]$. These micro explosions are used as a means for large explosion. 
Teller-Ulam two-stage thermonuclear bomb design

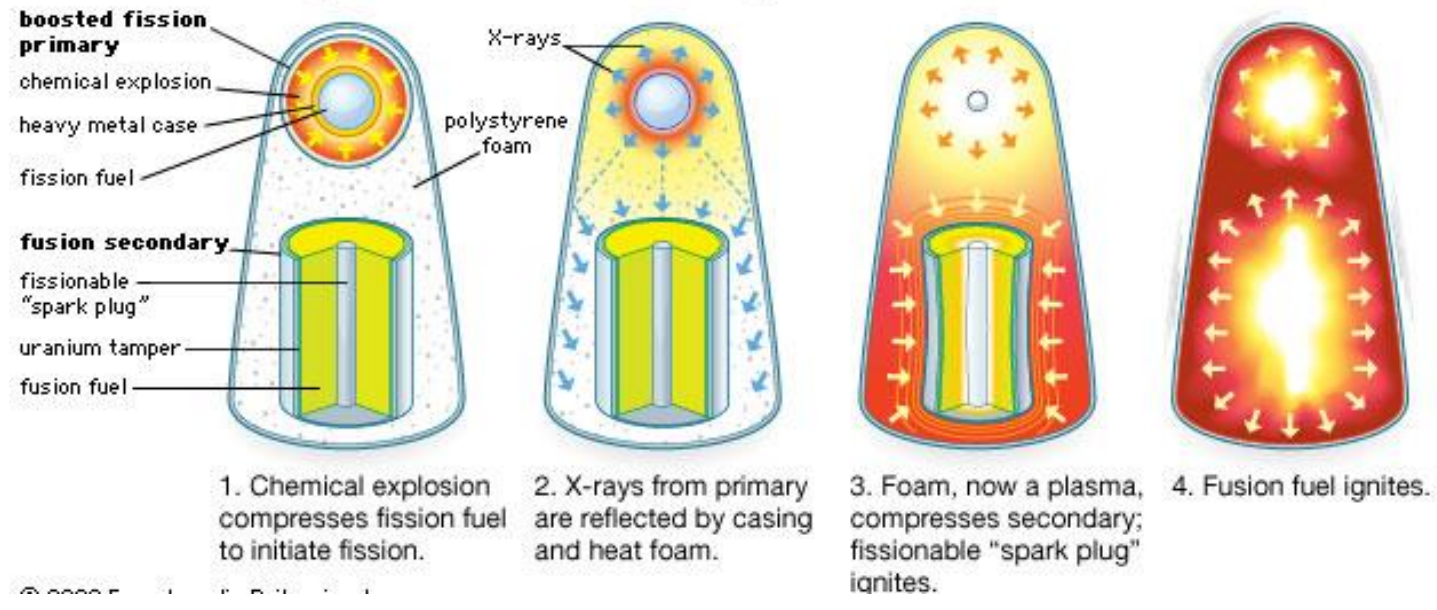

Fig - 1: Teller - Ulam design

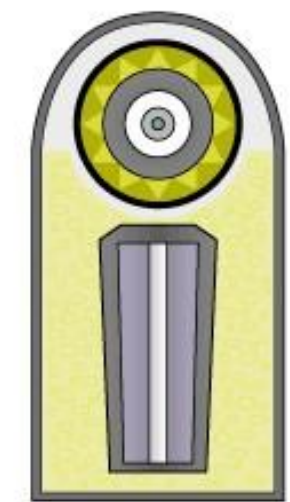

1. Warhead before

$\begin{array}{cc}\text { 1. Warhead before } & \text { 2. HE fires in primary, } \\ \text { firing; primary (fission bomb) compressing plutonium }\end{array}$ at top, secondary (fusion fuel) at bottom, all suspen in polystyrene foam.

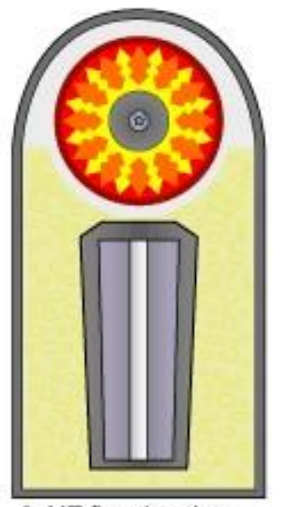
core into supercriticality reaction.

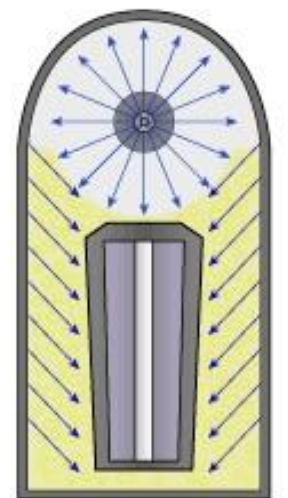

3. Fissioning primary emits $\mathrm{X}$-rays which reflect along the inside of

the casing, irradiating the polystyrene foam.

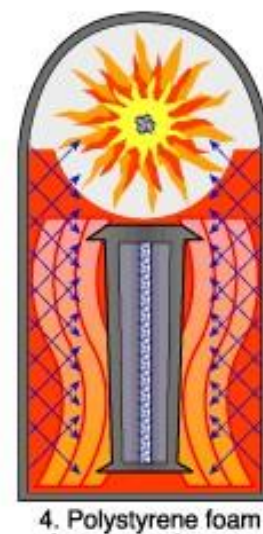

4. Polystyrene foam
becomes plasma, compressing secondary, and plutonium sparkplug begins to fission.

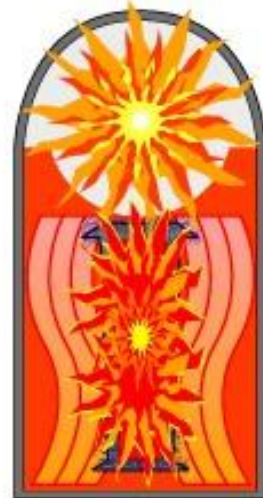

5. Compressed and heated, lithium-6 deuteride fuel begins fusion reaction, ne flux causes tamper to fission.
A fireball is starting to form...

Fig - 2: (a) Modified Teller - Ulam design (Mike Ivy) (Two stage device ignition, micro explosion, detonation, and explosion mechanisms explained schematic) 


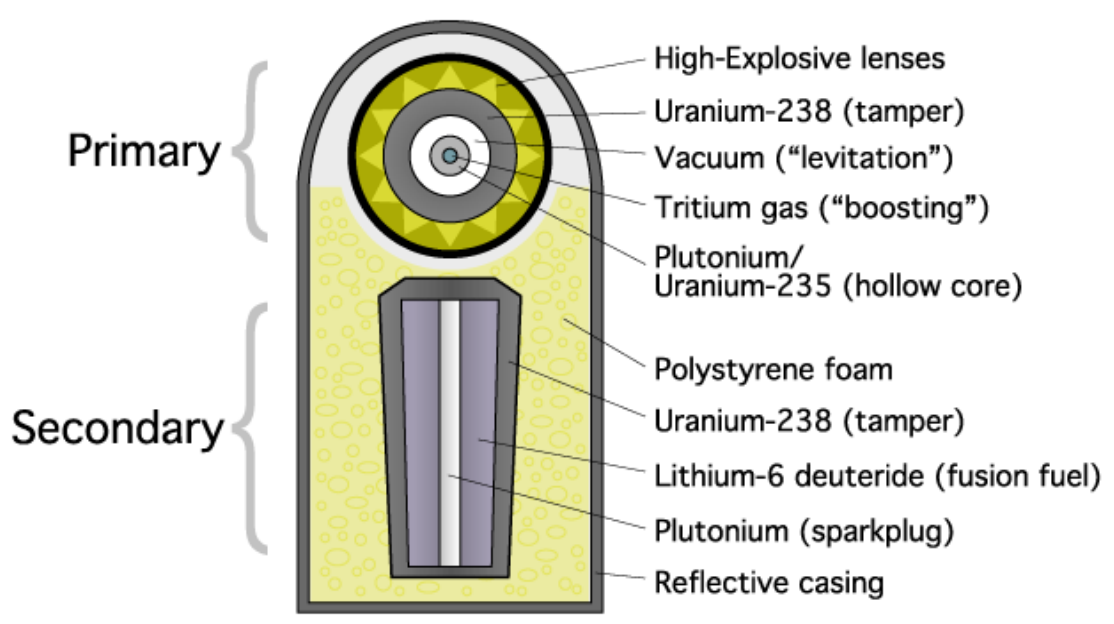

Fig - 2: (b) Modified Teller - Ulam design (Mike Ivy) (Two stage device parts explained schematic)

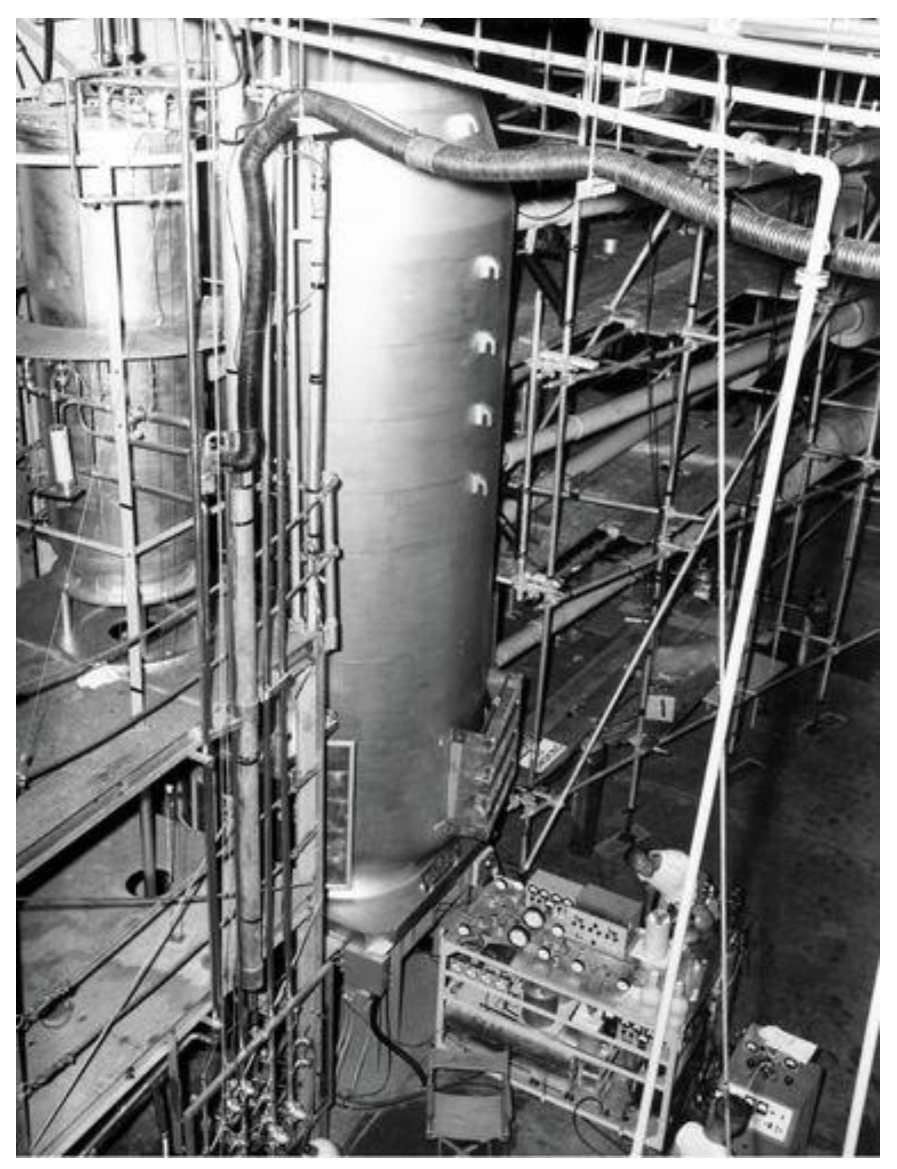

Fig - 3: Modified Teller - Ulam design (Mike Ivy) [4]

Devices may be designed and build on many principles some of them include (a) energy basis, (b) yield basis and (c) weight basis. The latter is considered here. This is chosen on the basis of aircraft (High altitude plane B 52). Pay load bay area of plane serves as start point to determine 
the dimensions of shell of device. This is described briefly here (assuming it is rectangular section). Using standard arithmetic

$$
\text { Volume of rectangle }=\text { length } \mathrm{x} \text { width } \mathrm{x} \text { height }
$$

As no direct measurements are available, indirect measurements are made. It is known that payload bay area can accommodate $51 \mathrm{Mk} 82$ bombs each $500 \mathrm{llbs}$, totaling 25,500 lbs - weight carrying capacity of typical B52G stratosphere. This is used as benchmark. Dimensions of typical Mk 82 are (Fig 4)

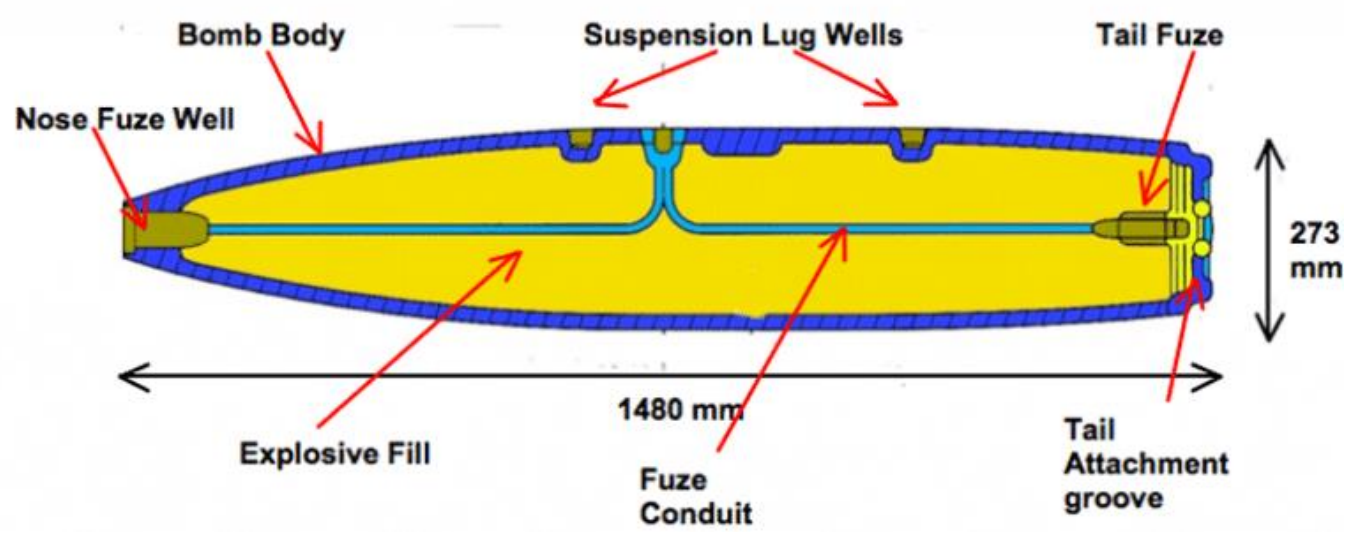

Fig - 4: Typical Mk 82

From this dimension of payload bay area are calculated which can contain our device.

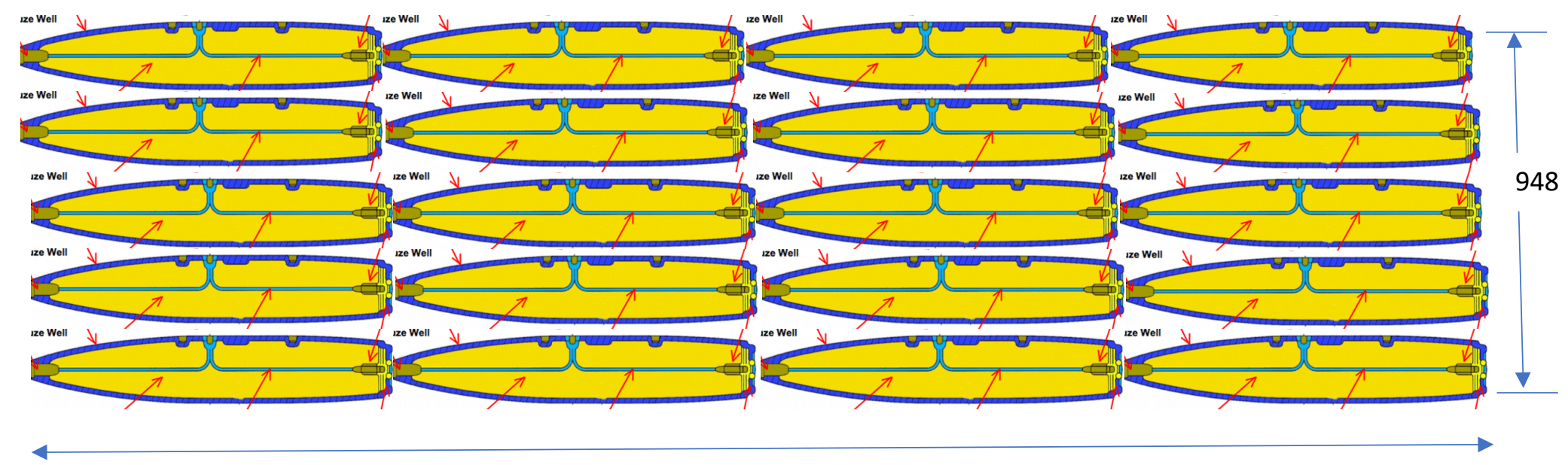

\section{$5920 \mathrm{~mm}$}

Fig - 5: Typical payload dimensions of B52G [3 x 1 Layer $($ One layer $=20$ devices $)]$ Putting in equation 1

Volume of rectangle $=5920 \mathrm{~mm} \times 948 \mathrm{~mm} \times 819 \mathrm{~mm}$ 
Further design is carried out using these dimensions and weight.

\section{Design and materials}

From above calculations it is inferred that roughly a rolled piece of $24 \mathrm{mx} 1 \mathrm{~m}$ is required which may be cut into further dimensions. Thickness of plate is determined from energy release and energy release rate which is determined by heat transfer pattern upon explosion and any effects of implosion (Section 3). This is manufactured from HEA in cold rolled and annealed condition with pronounced texture and elongated grains along rolling direction. Furter, a definite orientation relationship is ascertained and maintained along the rolling direction. HEAs selected for this are chosen from a wide variety of HEAs available. This is briefly described here. Typically, material for device must possess high strength, high hardness, ductility, formability, drawability, and anisotropic properties. High entropy alloys (HEA) are new class of materials [13-18] which nicely fulfils this requirement. Essentially, they are solid solutions of multi principal [17] elements (usually $>5$ ) in equiatomic percentages [19, 20] eliminating the need of base metal as in conventional alloys. This gives them many unique properties which may be tailored at will (heat treatment, cold rolling [21-26], precipitation [27-31], irradiation [32]). They also exhibit excellent directional properties [33] with formation of distinct twins [34-36], faults [37], dislocation evolution sites, texture [22, 23, 25, 26, 33, 38-45] and bands along certain preferred crystallographic planes even in hexagonal close packed structures [34-36, 46]. These anisotropic properties are strong function of rolling [21-26], working, or forging (swaging) [47] direction and annealing temperature and can be utilized to benefit. This study encompasses making outer shell of a typical fusion device selected on the basis of the weight, which is a function of area of pay load bay of carrier aircraft. As a combination of excellent strength, hardness and low to moderate ductility is required, two phase $\mathrm{Al}_{0.5} \mathrm{CoCrFeNi}$ [21] is chosen as model alloy. It has two phases namely BCC and FCC which gives it's a unique place in alloys category. It has excellent mechanical properties especially cold workability. It can be successfully cold reduced to $80 \$$ reduction without any failure. This is one of main reasons to employ it as material of outer shell of device. At this reduction, it is reported to have maintained $480 \mathrm{Hv}$ hardness, $1396 \mathrm{MPa}$ yield strength and $1461 \mathrm{MPa}$ tensile strength indicating cold working substantially increase its properties. These superior properties are attributed to strong dislocation interaction due to dislocation pile up and accumulation and deformation twinning and lattice distortion. A strong texture is generated by cold rolling along $\{110\}<112>$ and $\{111\}<110\rangle$. This can be effectively removed through fully recrystallization in which case weak $<110>/ / \mathrm{ND}$ and $<111>/ / \mathrm{RD}$ texture is detected. Poles figures describing evolution of this texture are described below 
(a)
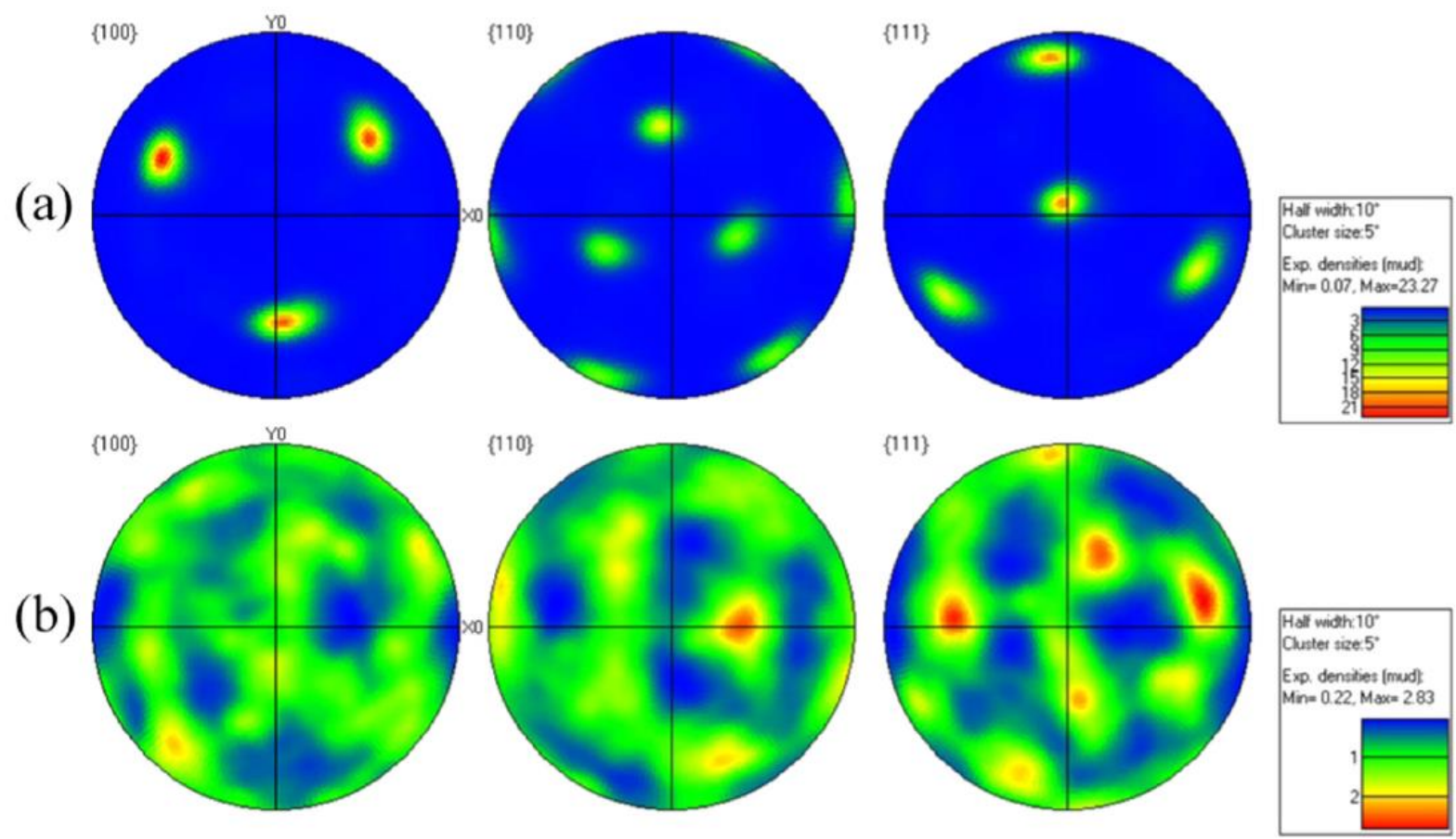

Fig - 6: Pole figure of $\mathrm{Al}_{0.5} \mathrm{CoCrFeNi}$ annealed at (a) $900^{\circ} \mathrm{C}$ and (b) $1200^{\circ} \mathrm{C}$ [21]
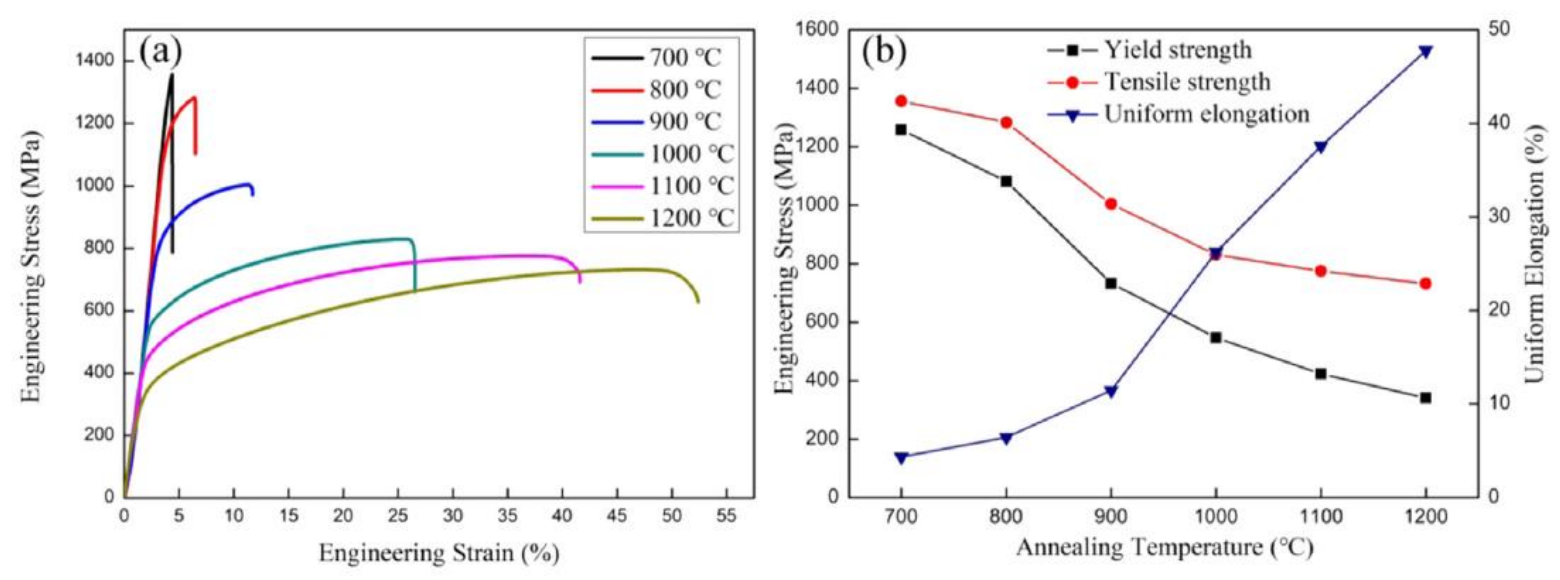

Fig - 7: (a) Engineering stress Vs Engineering strain plots and (b) Engineering stress and UTS varying with annealing temperature [21]

Figure 7, part a describes relationship of engineering stress with engineering strain for named alloy and part $b$ of figure describes its variation with annealing temperatures. It can be easily seen that Engineering stress decreases while UTS increases with rise of annealing temperature indicating activation of softening (dislocation assimilation) and strengthening (dislocation pile up and twining [34, 35, 41, 48-51]) mechanisms. 


\section{Heat transfer analysis}

Heat transfer analysis is performed to determine effective thickness which will not undergo gross rupture upon exposure to intense amount of heat radiation. Instead, its rupture is determined by initiation of crack of certain length which will exceed critical length, grow and then propagation along certain preferred crystallographic planes only (pre-determined from texture studies and calculations and orientation relationships). Rupture along these planes will help determine and optimize device parameters (set earlier) for effective explosion, blast, and yield. This is described elsewhere.

\section{Conclusion}

High entropy alloys with ability to exhibit and manifest anisotropy and directional properties along a certain crystallographic plane parallel to rolling direction are chosen as material $\left(\mathrm{Al}_{0.5} \mathrm{CoCrFeNi}\right)$ of choice. They can be reduced to less than $80 \%$ without failure. They are proposed to exhibit texture as measured by pole and inverse pole figures and orientation relationships. They are formed by combination of rolling (cold) and annealing heat treatment. Dislocation pileup and twinning mechanisms are attributed to increased strength in these during cold working while dislocation assimilation are attributed to softening during annealing.

\section{References}

1. The Physical Principles of Thermonuclear Explosive Devices. Von F. Winterberg, Fusion Energy Foundation, 1981 (New York/N.Y. 10019, 888 Seventh Ave), 144 S. \$ 9.95. Physik in unserer Zeit, 1983. 14(5): p. 160-160.

2. Siracusa, J.M., Nuclear Weapons: A Very Short Introduction. 2015: Oxford University Press.

3. Barnaby, F., How to Build a Nuclear Bomb: And Other Weapons of Mass Destruction. 2004: Nation Books.

4. Wellerstein, A., John Wheeler's H-bomb blues. Physics Today, 2019. 72(12): p. 42-51.

5. Holloway, D., Special Issue: New Light on Early Soviet Bomb Secrets. Physics Today, 1996. 49(11): p. 26-27.

6. Jonter, T., Getting rid of the Swedish bomb. Physics Today, 2019. 72(9): p. 40-47.

7. Hansen, C., The Swords of Armageddon. 2007: Chukelea publications.

8. Sandel, F.L., et al., Focusing of fast plasma shock waves. The Physics of Fluids, 1975. 18(8): p. 1075-1076.

9. Winterberg, F., Shock wave focusing by curved walls and staging of beam induced thermonuclear microexplosions. Journal of Plasma Physics, 1976. 16(1): p. 81-94.

10. Winterberg, F., Thermonuclear microexplosion ignition by imploding a disk of relativistic electrons. Physics of Plasmas, 1995. 2(3): p. 733-740.

11. Winterberg, F., Adiabatic wall focusing of intense ion beams for the ignition of thermonuclear microexplosions. Zeitschrift für Physik A Atoms and Nuclei, 1977. 282(1): p. 3-6.

12. Winterberg, F., Thermonuclear micro-explosions with intense ion beams. Nature, 1974. 251(5470): p. 44-46.

13. George, E.P., D. Raabe, and R.O. Ritchie, High-entropy alloys. Nature Reviews Materials, 2019. 4(8): p. 515-534.

14. Wei, S., F. He, and C.C. Tasan, Metastability in high-entropy alloys: A review. Journal of Materials Research, 2018. 33(19): p. 2924-2937. 
15. Xin, Y., et al., High-Entropy Alloys as a Platform for Catalysis: Progress, Challenges, and Opportunities. ACS Catalysis, 2020. 10(19): p. 11280-11306.

16. Ye, Y.F., et al., Design of high entropy alloys: A single-parameter thermodynamic rule. Scripta Materialia, 2015. 104: p. 53-55.

17. Ye, Y.F., et al., High-entropy alloy: challenges and prospects. Materials Today, 2016. 19(6): p. 349-362.

18. Zhang, Y., et al., Microstructures and properties of high-entropy alloys. Progress in Materials Science, 2014. 61: p. 1-93.

19. Cantor, B., et al., Microstructural development in equiatomic multicomponent alloys. Materials Science and Engineering: A, 2004. 375-377: p. 213-218.

20. Sonkusare, R., et al., Phase equilibria in equiatomic CoCuFeMnNi high entropy alloy. Materials Chemistry and Physics, 2018. 210: p. 269-278.

21. Guo, T., et al., Microstructure and properties of bulk Al0.5CoCrFeNi high-entropy alloy by cold rolling and subsequent annealing. Materials Science and Engineering: A, 2018. 729: p. 141-148.

22. Kaushik, L., et al., Deformation mechanisms and texture evolution in high entropy alloy during cold rolling. International Journal of Plasticity, 2021. 141: p. 102989.

23. Sathiaraj, G.D. and P.P. Bhattacharjee, Effect of cold-rolling strain on the evolution of annealing texture of equiatomic CoCrFeMnNi high entropy alloy. Materials Characterization, 2015. 109: p. 189-197.

24. Sathiaraj, G.D., et al., The effect of heating rate on microstructure and texture formation during annealing of heavily cold-rolled equiatomic CoCrFeMnNi high entropy alloy. Journal of Alloys and Compounds, 2016. 688: p. 752-761.

25. Shabani, A. and M.R. Toroghinejad, Evaluation of microstructure and texture formation during annealing of cold-rolled FeCrCuMnNi multiphase high-entropy alloy. Transactions of Nonferrous Metals Society of China, 2020. 30(2): p. 449-462.

26. Wani, I.S., et al., Cold-rolling and recrystallization textures of a nano-lamellar AlCoCrFeNi2.1 eutectic high entropy alloy. Intermetallics, 2017. 84: p. 42-51.

27. Cho, K., et al., Grain refinement of non-equiatomic Cr-rich CoCrFeMnNi high-entropy alloys through combination of cold rolling and precipitation of $\sigma$ phase. Materials Science and Engineering: A, 2018. 735: p. 191-200.

28. Gwalani, B., et al., Dynamic Shear Deformation of a Precipitation Hardened AlO.7CoCrFeNi Eutectic High-Entropy Alloy Using Hat-Shaped Specimen Geometry. Entropy, 2020. 22(4).

29. He, J.Y., et al., A precipitation-hardened high-entropy alloy with outstanding tensile properties. Acta Materialia, 2016. 102: p. 187-196.

30. Sinha, S., et al., Revealing the microstructural evolution in a high entropy alloy enabled with transformation, twinning and precipitation. Materialia, 2019. 6: p. 100310.

31. Zhao, Y.L., et al., Heterogeneous precipitation behavior and stacking-fault-mediated deformation in a CoCrNi-based medium-entropy alloy. Acta Materialia, 2017. 138: p. 72-82.

32. Xia, S.-q., et al., Irradiation Behavior in High Entropy Alloys. Journal of Iron and Steel Research, International, 2015. 22(10): p. 879-884.

33. Sathiaraj, G.D., A. Pukenas, and W. Skrotzki, Texture formation in face-centered cubic highentropy alloys. Journal of Alloys and Compounds, 2020. 826: p. 154183.

34. Jiang, S., Z. Jiang, and Q. Chen, Deformation twinning mechanism in hexagonal-close-packed crystals. Scientific Reports, 2019. 9(1): p. 618.

35. Wang, H., et al., A constitutive model of twinning and detwinning for hexagonal close packed polycrystals. Materials Science and Engineering: A, 2012. 555: p. 93-98. 
36. Wang, H., et al., A crystal plasticity model for hexagonal close packed (HCP) crystals including twinning and de-twinning mechanisms. International Journal of Plasticity, 2013. 49: p. 36-52.

37. Zhao, S., G.M. Stocks, and Y. Zhang, Stacking fault energies of face-centered cubic concentrated solid solution alloys. Acta Materialia, 2017. 134: p. 334-345.

38. Asoushe, M.H., et al., Thermal stability, microstructure and texture evolution of thermomechanical processed AlCoCrFeNi2.1 eutectic high entropy alloy. Materials Science and Engineering: A, 2021. 799: p. 140012.

39. Beyerlein, I.J., et al., Texture evolution via combined slip and deformation twinning in rolled silver-copper cast eutectic nanocomposite. International Journal of Plasticity, 2011. 27(1): p. 121-146.

40. Bhattacharjee, P.P., et al., Microstructure and texture evolution during annealing of equiatomic CoCrFeMnNi high-entropy alloy. Journal of Alloys and Compounds, 2014. 587: p. 544-552.

41. Haase, C. and L.A. Barrales-Mora, Influence of deformation and annealing twinning on the microstructure and texture evolution of face-centered cubic high-entropy alloys. Acta Materialia, 2018. 150: p. 88-103.

42. Lu, P., et al., Mechanical behaviors and texture evolution of CoCrFeNi high-entropy alloy under shear-tension deformation. Journal of Alloys and Compounds, 2020. 815: p. 152479.

43. Sathiaraj, G.D., et al., Effect of heavy cryo-rolling on the evolution of microstructure and texture during annealing of equiatomic CoCrFeMnNi high entropy alloy. Intermetallics, 2016. 69: p. 1-9.

44. Wani, I.S., et al., Evolution of microstructure and texture during thermo-mechanical processing of a two phase AlO.5CoCrFeMnNi high entropy alloy. Materials Characterization, 2016. 118: p. 417-424.

45. Wu, Y., et al., Study of Texture Analysis on Asymmetric Cryorolled and Annealed CoCrNi Medium Entropy Alloy. Crystals, 2020. 10(12): p. 1154.

46. Fang, Q., et al., Probing the phase transformation and dislocation evolution in dual-phase highentropy alloys. International Journal of Plasticity, 2019. 114: p. 161-173.

47. Laplanche, G., et al., Microstructural evolution of a CoCrFeMnNi high-entropy alloy after swaging and annealing. Journal of Alloys and Compounds, 2015. 647: p. 548-557.

48. Christian, J.W. and S. Mahajan, Deformation twinning. Progress in Materials Science, 1995. 39(1): p. 1-157.

49. Clayton, J.D., Deformation Twinning in Single Crystals, in Nonlinear Elastic and Inelastic Models for Shock Compression of Crystalline Solids, J.D. Clayton, Editor. 2019, Springer International Publishing: Cham. p. 275-327.

50. Huang, S., et al., Twinning in metastable high-entropy alloys. Nature Communications, 2018. 9(1): p. 2381.

51. Sun, S.J., et al., Transition of twinning behavior in CoCrFeMnNi high entropy alloy with grain refinement. Materials Science and Engineering: A, 2018. 712: p. 603-607. 